\title{
Análisis de la propuesta diseño de Marca Ciudad para Manta
}

\section{Analysis of the proposed design of the City Brand for Manta}

\author{
Gabriela Lourdes Vélez Bermello ${ }^{1}$ \\ ${ }^{1}$ Universidad Estatal Península de Santa Elena \\ *gvelezb@upse.edu.ec
}

DOI: https://doi.org/10.26871/killkana_social.v3i3.518

\begin{abstract}
Resumen
Manta es una ciudad de Ecuador que durante sus años de cantonización no posee una marca ciudad, la cual resulta tan necesaria en estos tiempos de globalización. El presente artículo muestra desde el punto de vista comunicacional semiótico, un análisis de propuesta de diseño que está basado en una amplia investigación como parte de un proyecto universitario, el mismo que aplica diferentes métodos y técnicas de investigación. Entre ellos, los grupos focales y las encuestas que sirvieron para conocer cuáles son los íconos representativos de la ciudad, sus colores y formas que la caracterizan para que en base a un diseño se fecunde una marca para Manta; y que identifiquen a una población con más de 200 mil habitantes. La investigación también se sustenta en teóricos que enlazan la comunicación, publicidad, marketing y otros aspectos que convergen entre sí. La silla manteña, un símbolo posicionado en la mente de los manteses destaca como referente a la hora de construir una idea de marca.
\end{abstract}

Palabras clave: Comunicación; Ecuador; íconos Marca ciudad; Manta; Silla Manteña.

\begin{abstract}
Manta is a city in Ecuador that during its cantonization years does not have a city brand, which is so necessary in these times of globalization. This article shows, from the semiotic communication point of view, an analysis of a design proposal that is based on extensive research as part of a university project, which applies different research methods and techniques. Among them, the focus groups and the surveys that served to know which are the representative icons of the city, its colors and shapes that characterize it so that based on a design a brand for Manta is fertilized; and that identify a population with more than 200 thousand inhabitants. The research is also based on theorists that link communication, advertising, marketing and other aspects that converge with each other. The manteñ chair, a symbol positioned in the minds of the Mantes, stands out as a reference when it comes to building a brand idea.
\end{abstract}

Keywords: City brand; communication; Ecuador; Blanket; Manteña Chair; icons.

\section{Introducción}

La investigación tiene como propósito presentar un posible diseño de Marca Ciudad para la Manta, el mismo que está sustentado por los resultados de un proyecto de investigación financiado por la Universidad Laica Eloy Alfaro de Manabí (ULEAM) y el cual fue denominado: Signos visuales contemporáneos de identidad urbana de Manta y construcción de la marca ciudad.

\subsection{Breves antecedentes de la ciudad}

Manta es un cantón de Manabí, una de las 24 provincias que tiene Ecuador, país localizado en Sudamérica. Por su ubicación costanera, la ciudad posee diversidades como, la pesca, deportes, cultura, gastronomía, turismo, entre otros. Tiene una población de 226,477 habitantes (INEC 2010).

La ciudad, se remonta a los orígenes de la cultura Manteña-Huancavilca, en el llamado periodo de integración de las culturas prehispánicas del Ecuador, Holm (1982) indica que la cultura manteña se desarrolló en la costa ecuatoriana entre los años 800 a 1530 Después de Cristo.

Estrada (1957) distinguió en sus estudios a los manteños del norte situados en Bahía, Manta y Portoviejo, y los manteños del sur o Huancavilcas que ocuparon el Golfo de Guayaquil, la Isla Puná y Colonche. Una diferencia fundamental entre los manteños del norte y del sur, es que los primeros trabajaban la piedra para elaborar elementos significativos de su cultura como la silla U.

La cultura manteña propiamente dicha, tenía una estructura de dominio político-espacial representada en los llamados señoríos. Junto a Picoazá y Salangome el señorío de Jocay era uno de los principales y se asentaba en lo que hoy es la ciudad de Manta (Sánchez-Ramos, s.f.).

El arqueólogo Marshall Saville quien inició en 1906 el descubrimiento de los vestigios de la cultura manteña, fue el único que logró ver las ruinas del antiguo señorío de 
Jocay e identificar las formas de sus viviendas y sus modos productivos con la agricultura en terrazas y el comercio marítimo mediante una liga de mercaderes (Sánchez-Ramos, s.f.).

Este recuento histórico, pretende destacar que en la actualidad existe una marca institucional del Gobierno Autónomo Descentralizado de Manta (GAD) cuyo símbolo es la silla manteña, la misma que se mantiene en constructo visual de los ciudadanos (Silla Manteña, imagen que identifica al GADM-Manta, 2018), pese a que la silla no es un ícono único de la ciudad.

\subsection{Manta actual tras el 16 de abril}

Precisamente por ser Manta una ciudad de matices, la cual tiene su génesis en el año 1824 cuando se convirtió en cantón y en donde ha sobresalido la cultura indígena de mercaderes, la caleta de pescadores, el puerto agroexportador y pesquero y la ciudad mestiza y cosmopolita en la que conviven ejes productivos y culturas diversos debido a la migración y el desarrollo; además, de haber padecido el 16 de Abril de 2016 un terremoto que devastó un punto importante para el comercio, el sector denominado como Tarqui, modificando las infraestructuras y sus patrimonios arquitectónicos, resulta pertinente presentar este manuscrito que tiene entre sus objetivos reflejar la forma geométrica por las cuales se inclinaron los ciudadanos en base a la metodología empleada, así como los colores y, sobre todo, el ícono identitario de dicho territorio.

En el presente la ciudad se orienta, -y así lo califica el Plan de desarrollo y de ordenamiento territorial del Gobierno Autónomo Descentralizado del Cantón Manta 2012 2020- como un eje generador de movimientos comerciales y turísticos, sin dejar de ponderar sus servicios portuarios y aeroportuarios, sus asentamientos industriales ligados a la actividad pesquera y a los emprendimientos de la pesca artesanal y otros sectores como la manufactura de grasas y oleaginosas (Actualización del plan de desarrollo y ordenamiento territorial con especial énfasis en la gestión del riesgo Manta -2019, 2020).

Manta fue declarada oficialmente en 1999 como Primer Municipio Turístico del Ecuador mediante decreto firmado por el Presidente de la República, Jamil Mahuad Witt. Los flujos turísticos provienen principalmente del turismo de temporada playera (entre diciembre y marzo) y vacaciones de la sierra ecuatoriana (entre julio y agosto).

En cuanto a la visita de extranjeros, éstas se relacionan más con las temporadas de cruceros. Para la Cámara de Turismo de Manta, estos últimos flujos, representan un promedio de 50 mil visitantes al año (A los turistas de crucero les gusta conocer Manta caminando, 2020).

\subsection{Marca Ciudad Manta}

Para todo este cúmulo de devenires, este trabajo se realiza con el fin de asentar la definición de ciudad que tiene Manta puesto que hasta la fecha no tiene una identidad que los respalde a nivel local como internacional, la aproximación hacia diseños de marca para Manta han tenido tintes políticos o municipales que quedan en el olvido con cada cambio de alcaldías. Así lo indica Castillo (2016) en un estudio denominado, El city branding en situaciones de emergencia: una aproximación a la promoción de Manta tras el terremoto y en el cual previamente hace un recuento de los diseños de marca institucional, destacando el isotipo Manta te inspira, creado en el departamento de Comunicación siguiendo los lineamientos gráficos del Estado ecuatoriano y el de la Silla Manteña, que está posicionada en la mente de los ciudadanos.

Para Bellet \& Llop (2004). los espacios urbanos van más allá de localidades geográficas, puesto que las ciudades funcionan como sistemas elaborados de significaciones, cuya sociedad responde a símbolos y está marcada por ellos. A tono con esto Barthes (2003) considera que la ciudad es un discurso, un verdadero lenguaje con el que habla a sus habitantes, y a su vez éstos hablan la ciudad y "la ciudad, al igual que la lengua, refleja la cultura: un mundo de significaciones compartidas" (Margulis, 2002, p.516).

Esas significaciones pueden ser compartidas materialmente como sonidos, formas visuales, íconos logos y otras representaciones de marca. Y las marcas son portadoras de significados. Es más, las marcas descansan en un significado. Depende de sus gestores que sea un buen o mal significado (Calle, 2008, p.15).

Respecto a las marcas, éstas, a más de ser nombres y símbolos, configuran percepciones y sentimientos de los consumidores y lo que el producto significa para ellos (Yejas, 2016).

Como nexo para la fusión de la ciudad a una marca de consumo colectivo es importante que ésta contenga no una reducción visual, sino una condensación puesto que a decir de Robles (2015) la ciudad comprende las diferentes maneras de vivirla e interpretarla. Interpretaciones que la asumen los ciudadanos y sus sectores ejes en la posibilidad de referenciarlas mediante un discurso estratégico.

Dicho discurso puede apuntar a ser diferenciador y estar contenido en una marca territorial. Para Puig (2009), considerado el gurú de las marcas territoriales, las ciudades con marca son ciudades referenciales "(...) Ciudades que innovan. Que se rediseñan. Que sitúan siempre a los ciudadanos en el centro de sus decisiones, proyectos, estrategias y comunicación. Ciudades que piensan. Y hacen. Ciudades que brillan. Ciudades siempre despiertas" (p. 11). Este experto español en gestión cultural afirma que el diseño o rediseño de una marca ciudad debe ser un acto de confianza, una apuesta a una ciudad de valores espléndidos consensuada entre los ciudadanos e impulsada desde lo público. La ciudad es la marca y el estilo con los que los ciudadanos quieren vivir y convivir y asumir el mundo cambiante, afirma Puig (2009).

Frente a una ciudad como Manta con un perfil urbano diverso y no menos complejo se hizo pertinente requerir de sus actores estratégicos la forma en que perciben el 
dinamismo de la urbe las representaciones que provoca y que elementos la simbolizan, así como la forma en que es vivida y habitada por sus ciudadanos como una práctica particular.

Partiendo por ejemplos de otras ciudades que han logrado tener una marca ciudad, las experiencias en el tiempo de dedicación varían según la cultura y el contexto, pues muchos autores coinciden que la construcción de una marca puede durar semanas como años en concebirla. Nueva York, Chile, París, México, son ciudades que hoy por hoy tiene posicionada su marca ciudad y en cada una sus tiempos de diseño han sido distintos e incluso, dentro del acontecer histórico, hay numerosas ciudades o países que han sido capaces de sobreponerse a situaciones de crisis, mediante una gestión efectiva de su marca (Seisdedos, 2006)

La tarea de englobar todo lo que es Manta en un diseño resulta un reto y en esa búsqueda esta investigación busca traducir lo que es la ciudad y que pronto esta tenga dicha marca en los productos y actividades que genera a diario.

\section{Metodología}

La presente investigación se basó en un trabajo cualitativo y cuantitativo que tiene varias fases que se explicará a continuación:

Primera etapa: A inicios del 2016 se realizó una revisión en la web para determinar los elementos simbólicos de Manta, con el objetivo de que posteriormente se hiciera una revisión y análisis de referentes teóricos.

Segunda etapa: Se aplicó la técnica del Focus Group por dos ocasiones, reuniendo en varias mesas de trabajo a representantes de los diversos sectores de Manta. El fin de esta actividad era conocer las visiones y percepciones que tienen sobre Manta.

La lectura de los grupos focales generados con este propósito responde no solo a un ejercicio de pertenencia o de autoafirmación colectiva, sino esencialmente a buscar una visión de ciudad significativa y factible de ser simbolizada en un discurso visual como resultado de una participación ciudadana que estimare la necesidad de buscar nuevas oportunidades para la ciudad a partir de una marca territorial.

Tercera etapa: Encadenando la etapa anterior y amparada en las percepciones de los integrantes de los Focus Group, se desarrolló un estudio de campo, mediante la realización de encuestas físicas. También se hicieron 11 entrevistas en profundidad a diversos ciudadanos que sirvieron básicamente para detectar qué tipo de conocimiento tenían en cuanto a lo que era Marca Ciudad, sin embargo, dichas interrogantes sirvieron como actividad interna de la investigación.

En esta misma fase se aplicaron encuestas On Line sobre los signos identitarios para ampliar la cobertura de encuestas físicas. Se sistematizaron los datos y se determinó cuáles son los signos, símbolos e íconos identitarios de Manta.
Las encuestas fueron previamente validadas entre un equipo de estudiantes y docentes de la universidad Laica Eloy Alfaro de Manabí.

Cuarta etapa: Bajo la obtención y sistematización de los resultados se elaboró una propuesta de diseño de Marca Ciudad.

\subsection{Población y muestra}

De una población de 226,477 habitantes (INEC 2010) se desarrollaron 1.383 encuestas físicas y 900 encuestas en línea. Se efectuaron dos Grupos Focales con 30 (cada uno) representantes de sectores estratégicos de Manta.

\section{Resultados}

Resultados de las encuestas físicas y online. De las 6 preguntas realizas se ha seleccionado a las tres que servirían de ejes para el diseño de la marca ciudad para Manta.

Tabla 1: ¿Cuál considera usted que identifica a Manta?

\begin{tabular}{cc}
\hline Alternativa & Porcentaje \\
\hline Monumento al Atún & $36 \%$ \\
Atardecer & $4 \%$ \\
Silla Manteña & $22 \%$ \\
Pesca & $13 \%$ \\
Playa & $18 \%$ \\
Trabajo & $6 \%$ \\
\hline
\end{tabular}

Fuente: Elaboración propia, bajo los resultados obtenidos en el Proyecto de Investigación

Tabla 2: ¿Cuál de las siguientes formas geométricas representaría mejor a Manta?

\begin{tabular}{cc}
\hline Alternativa & Porcentaje \\
\hline Triángulo & $28 \%$ \\
Circulo & $52 \%$ \\
Rombo & $17 \%$ \\
Ninguno & $1 \%$ \\
\hline
\end{tabular}

Fuente: Elaboración propia, bajo los resultados obtenidos en el Proyecto de Investigación

Tabla 3: ¿Cuál de los siguientes colores 1 evoca mejor a Manta?

\begin{tabular}{cc}
\hline Alternativa & Porcentaje \\
\hline 1 Azul & $38 \%$ \\
1 Celeste & $37 \%$ \\
1 Turqueza & $5 \%$ \\
1 Verde & $4 \%$ \\
1 Amarillo & $7 \%$ \\
1 Naranja & $4 \%$ \\
1 Blanco & $2 \%$ \\
1 Gris & $2 \%$ \\
\hline
\end{tabular}

Fuente: Elaboración propia, bajo los resultados obtenidos en el Proyecto de Investigación 


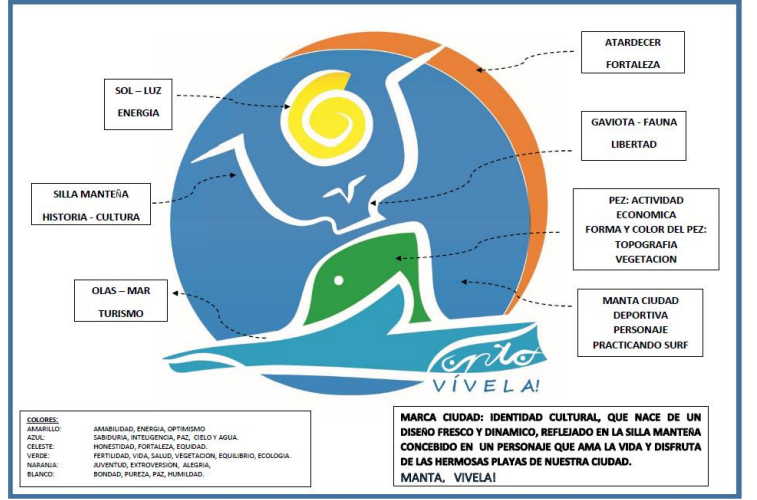

Figura 1: De acuerdo a los hallazgos encontrados se presenta la siguiente propuesta de diseño de Marca Ciudad para Manta

Este arte se concentra en la diversidad de colores que posee el territorio mantense, y basado en la información obtenida en la investigación realizada, predominan los colores celestes, evocando el aire y el cielo; el azul, reflejando las 13 playas: el naranja del atardecer; el verde, como parte del bosque de Pacoche, la vegetación, y el amarillo en el centro el Sol. Como máxima, está la Silla Manteña, pese a que en los resultados el Monumento al Atún está en primer lugar, este diseño se enfocó en la Silla Manteña por el posicionamiento que tiene en el constructo visual de las personas mantenses. La morfología del diseño está explicada en los recuadros superiores.

La imagen puede ser presentada en las siguientes versiones:

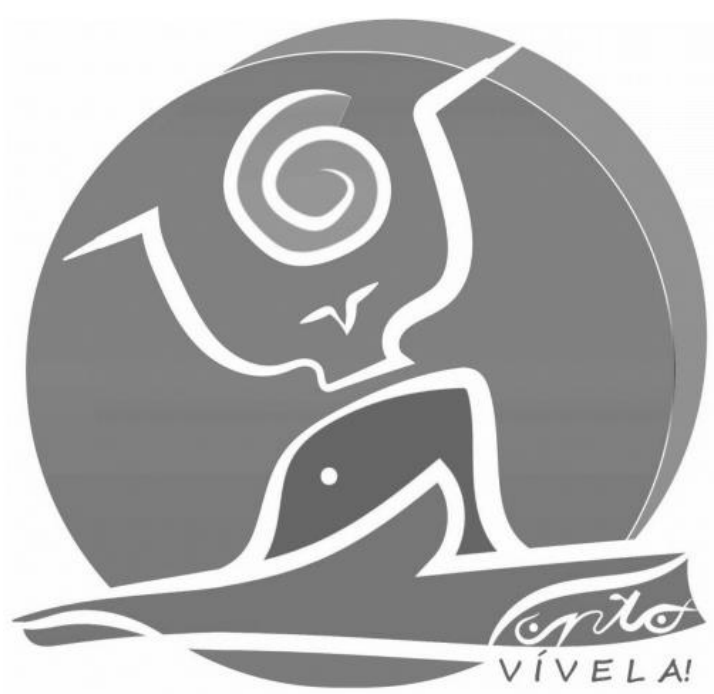

Monocromática

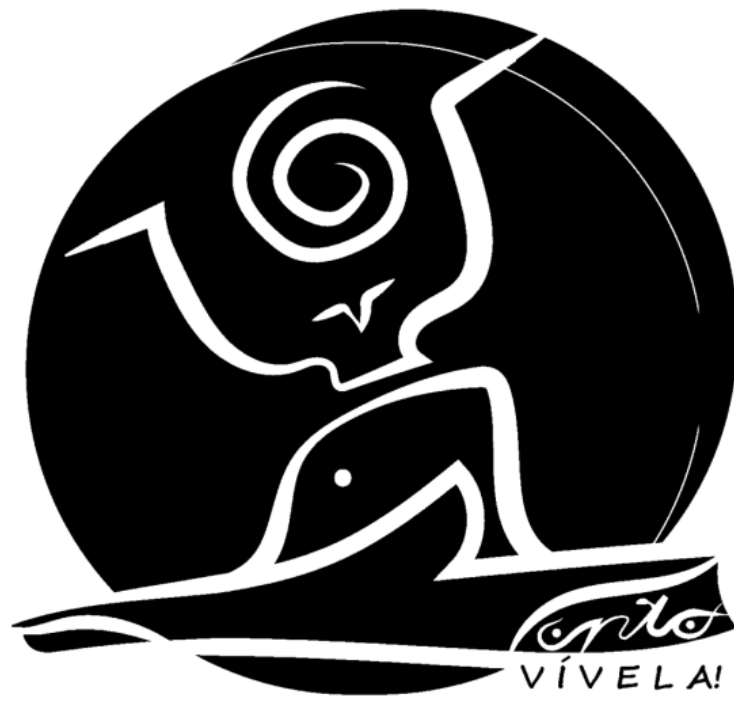

Blanco y Negro

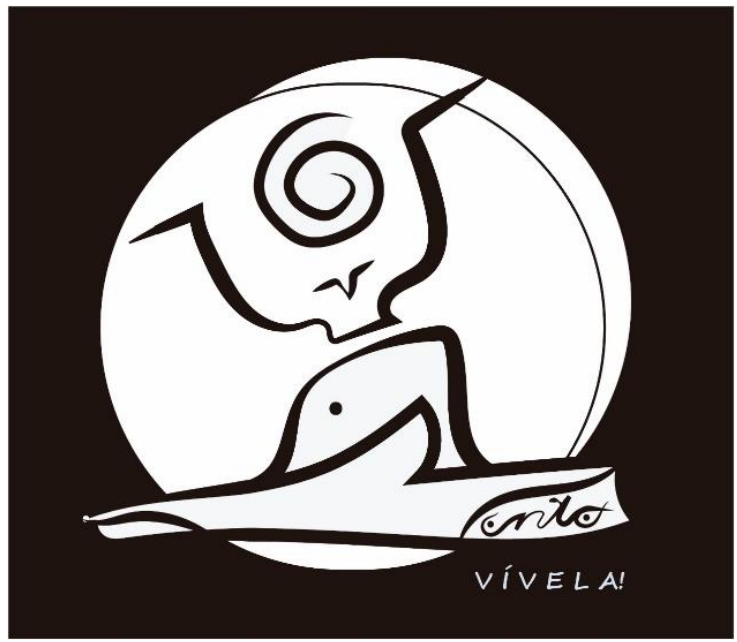

Negativo

\section{Discusión y Conclusiones}

En la búsqueda de una Marca Ciudad para Manta, hay que tener en cuenta que al ser los seres humanos diversos es imposible complacer a una totalidad, sin embargo, autores como Fuentes Martínez (2007) expresa varios parámetros a seguir al momento de pensar en una construcción de marca, para el investigador y estos serían: imagen ideal, imagen real e imagen estratégica.

Como parte del ideal es imprescindible mantener vivo los siguientes elementos: verbal, visual, cultural, objetual y ambiental, mientras que en lo real se debe tener en cuenta la percepción actual y finalmente en la imagen estratégica está el ver que dicho diseño se convierta entonces en un ideal para el entorno.

Partiendo de lo que expresa dicho investigador se podría asegurar que este manuscrito y sobre todo el diseño 
propuesto podrían abarcar con dichos parámetros, sin embargo, es evidente que podrían nacer nuevas ideas que sean justificadas y sobre todo aceptadas por la población.

Si bien las marcas son construidas por empresas, desde su origen mismo es concebida pensando en el consumidor, la identidad de una marca es la forma en la que una marca se hace visible y se materializa en los discursos que los actores sociales cruzan entre sí, la afectividad de una marca aumenta la capacidad de ser valorada si logra vincularse directamente con las "emociones" del consumidor.

El grupo objetivo al que va dirigido la marca ciudad de Manta está compuesto por el contexto social, cultural, político y económico, el contexto del mercado, la legislación, la competencia y las variaciones de la producción.

Por lo tanto, cada actor de la sociedad tiene que verse reflejado en dicha marca y pertenece al grupo objetivo al cual está dirigido, instituciones públicas, privadas, centros educativos, empresas, industrias, cada ciudadano o visitante de Manta.

En base a toda la investigación se obtienen las siguientes conclusiones:

Entre los íconos que identifican a Manta, resaltan: las playas, la actividad pesquera y la cultura.

Los resultados revelaron que el círculo es la forma geométrica que debe estar implementada en la Marca Ciudad de Manta y esto tiene similitud con la asociación que debe tener una Marca Ciudad con la Marca País.

Los colores azul y celeste predominan en los resultados de las encuestas y tiene correlación con la Marca Gestión, Marca Institucional del Municipio e incluso con las Marca que se promovió post terremoto.

De acuerdo a los resultados, si bien la ciudadanía no tiene un concepto claro de Marca Ciudad, sin embargo, reconoce que son los elementos simbólicos de la ciudad los que podrían representarla mejor y que, por lo tanto, hay que ir a una Marca Ciudad que, sobre todo, pase las diversas Marcas Gestión que han venido exponiéndose desde el gobierno municipal, durante los últimos años.

Es necesario que se genere una frase que fortalezca a la Marca Ciudad considerando las mismas potencialidades y simbolismos que la ciudadanía asocia con todo el constructor de ciudad Manta. Frases que sobrepasen el tiempo y circunstancias.

Dentro del proceso de creación de la marca ciudad de Manta se establece que el producto final puede estar a consideración de la ciudadanía para que sea aceptado tanto de manera local, nacional e internacional.

Con la finalidad de alcanzar este objetivo se recomiendan los siguientes procesos.

Estrategia de Marca: Definir la marca desde todos los puntos de vista. El grupo de investigación puede desarrollar el manual de marca que servirá de guía para los siguientes pasos y para todas aquellas personas que trabajen en la marca.
Identidad Corporativa: Se creó la imagen visible de la marca, de forma coherente con la estrategia de marca planteada previamente.

Plan de Marketing: Se propone el enfoque estratégico y las acciones necesarias para trasladar la promesa de la marca a todos los grupos de interés.

Desarrollo de piezas creativas: En función marca ciudad, esta pieza tendrá el objetivo de crear identificación y pertenencia de parte de la ciudadanía.

Promoción Web: Es vital que la marca tenga presencia y difusión online.

La marca ciudad podría tener varias aplicaciones Posibles aplicaciones, pues una de las estrategias que más se está usando para reforzar la imagen y posicionamiento de las ciudades es la de incrementar su presencia en diferentes soportes bien sean formatos digitales o impresos con el objetivo de posicionar su imagen en la mente de las personas tanto locales como de visitantes. La aplicación de la marca puede ser en diferentes soportes como: piezas publicitarias, papelería, vehículos, mobiliario urbanístico, entre otros.

\section{Referencias Bibliográficas}

Actualización del plan de desarrollo y ordenamiento territorial con especial énfasis en la gestión del riesgo manta -2019. (2020, Feb). Descargado de https://www.scribd.com/document/ 369534701/Actualizacion-del-plan -de-desarrollo-y-ordenamiento -territorial-con-especial-enfasis -en-la-gestion-del-riesgo-Manta $-2019$

Barthes, R. (2003). Cómo vivir juntos: simulaciones novelescas de algunos espacios cotidianos. Siglo XXI.

Bellet, C., y Llop, J. M. (2004). Miradas a otros espacios urbanos: las ciudades intermedias. Scripta Nova: revista electrónica de geografía y ciencias sociales, 2004, vol. 8, núm. 165, p. 1-28.

Calle, S. (2008). la marca cuidad de cuenca como elemento de participacion social. Buenos Aires, Argentina.

Castillo, P. S. (2016). El city branding en situaciones de emergencia: una aproximación a la promoción de manta tras el terremoto (Tesis de Master no publicada). Universidad de Especialidades Espíritu Santo.

Fuentes-Martínez, S. I. (2007). Sistema de gestión comunicacional para la construcción de una marca ciudad o marca país. Signo y pensamiento, 26(51), 80-97.

Holm, O. (1982). Cultura manteña-huancavilca. Museo Antropológico y Pinacoteca del Banco Central del Ecuador.

A los turistas de crucero les gusta conocer Manta caminando. (2020, Feb). Descargado de https://www.elcomercio.com/ actualidad/manta-turistas-crucero -conocer-statemdam.html accessed 3. Feb. 2020])
([Online; 
Margulis, M. (2002). La ciudad y sus signos. Estudios sociológicos, 515-536.

Puig, T. (2009). Marca ciudad: Como rediseñarla creativamente para afrontar diferencia y vida.

Robles, M. E. V. (2015). La estrategia de marca-ciudad en la función de turismo. El periplo sustentable(28), 59-80.

Seisdedos, H. (2006). La marca ciudad como antídoto para la"bonsainización"delçity marketing". Harvard Deusto Marketing y Ventas(76), 72-79.

Sánchez-Ramos, J. (s.f.).

Yejas, D. A. A. (2016). Estrategias de marketing digital en la promoción de marca ciudad. Revista Escuela de Administración de Negocios(80), 59-72. 